This document is published in:

International Journal of Plasticity, 2013, 40, 185-201.

Doi: http://dx.doi.org/10.1016/j.ijplas.2012.08.003.

(c) Elsevier 


\title{
On the Taylor-Quinney coefficient in dynamically phase transforming materials. Application to 304 stainless steel
}

\author{
R. Zaera ${ }^{\mathrm{a}, *}$, J.A. Rodríguez-Martínez ${ }^{\mathrm{a}}$, D. Rittel ${ }^{\mathrm{a}, \mathrm{b}}$

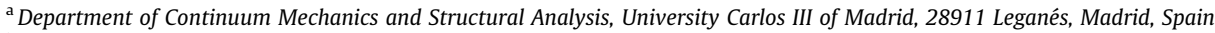 \\ ${ }^{\mathrm{b}}$ Faculty of Mechanical Engineering, Technion, 32000 Haifa, Israel
}

Keywords:

A. Phase transformation

Taylor-Quinney coefficient

B. Constitutive behavior

A. Thermomechanical process

C. Impact testing

\begin{abstract}
A B S T R A C T
We present a thermodynamic scheme to capture the variability of the Taylor-Quinney coefficient in austenitic steels showing strain induced martensitic transformation at high strain rates. For that task, the constitutive description due to Zaera et al. (2012) has been extended to account for the heat sources involved in the temperature increase of the material. These are the latent heat released due to the exothermic character of the transformation and the heat dissipated due to austenite and martensite straining. Through a differential treatment of these dissipative terms, the Taylor-Quinney coefficient develops a direct connection with the martensitic transformation becoming stress, strain and strain rate dependent. The improved constitutive description sheds light on experimental results available in the literature reporting unusual $(>1)$ values for the Taylor-Quinney coefficient.
\end{abstract}

\section{Introduction}

Many advanced processes in engineering such as high-speed metal forming (Rojek et al., 2001), cutting (Miguélez et al., 2009; Molinari et al., 2010; Ma et al., 2012), crash in energy absorbing structures (Reyes et al., 2002; Rusinek et al., 2008) or impact on metallic plates (Rosenberg and Dekel, 2004; Rodríguez-Martínez et al. (2010a,b)) involve large strains at high strain rates. In these conditions, the thermodynamic process deviates from the isothermal state and approaches adiabaticity, leading to large and sometimes very rapid variations in the temperature field. The analysis should then use temperaturedependent mechanical properties where thermal softening of the material should be considered since dynamic plastic instabilities, such as adiabatic shear bands or necking, are known to be temperature dependent (Molinari, 1997; BonnetLebouvier et al., 2002; Rodríguez-Martínez et al., 2010c).

The main source for temperature increase in the absence of external heat usually comes from plastic dissipation. In practice, a correct determination of this dissipation is needed for a proper evaluation of material softening in high strain rate applications. Following Tresca (1879), Farren and Taylor (1925) and Taylor (1934) were the first who observed that plastic work is not entirely converted into heat in the deformation of metals, so that part of it is stored in cold work - so-called stored energy of cold work - Bever et al. (1973). Following these seminal contributions, the Taylor-Quinney coefficient has been defined as the ratio of dissipated to plastic works (in its integral form $\beta_{\text {int }}$ ), or dissipated to plastic powers (in its differential form $\beta_{\text {diff }}$ ), as discussed by Rittel (1999). These coefficients are used to calculate the temperature increase in the simulation of dynamic processes. Here, it is important to note that the integral factor cannot exceed a value of 1 due to its very definition, a restriction that does not apply to instantaneous power ratios (Rittel, 1999).

\footnotetext{
* Corresponding author. Tel.: +34 916249983; fax: +34 916249430.

E-mail address: ramon.zaera@uc3m.es (R. Zaera).
} 
Different authors have measured these coefficients in polymers (Ravi-Chandar, 1995; Rittel, 1998; Bjerke et al., 2002) and metals (Mason et al., 1994; Chrysochoos et al., 1989; Kapoor and Nemat-Nasser, 1998; Hodowany et al., 2000; Oliferuk et al., 2004; Rittel et al., 2012) by using a variety of experimental techniques such as thermography, embedded thermocouples or high speed infrared detectors. For the sake of simplicity it is often assumed that the two $\beta$ factors are constant, usually taking a value lower than 1, or equal to 1 when all the plastic work is used to heat the material (Kapoor and Nemat-Nasser, 1998; Brünig and Driemeier, 2007; Baig et al., 2012; Khan and Liu, 2012). Once determined, they can be used in a model to calculate thermal output work as a fraction of the dissipated input plastic power. However, different authors reported a functional dependence of $\beta_{\text {int }}$ upon strain and/or strain rate (Bever et al., 1973; Mason et al., 1994; MacDougall, 2000; Rittel et al., 2006; Rusinek and Klepaczko, 2009; Rittel et al., 2012), a fact that may significantly complicate the solution of the coupled heat equation (Boley and Weiner, 1960).

When plastic deformation is governed by dislocation slip, this dependence has been explained through the effect of strain in the dislocation density increase and work converted into heat (Bever et al., 1973; Zehnder, 1991), as can be found e.g. in Benzerga (Benzerga et al., 2005). However additional processes may take place during plastic deformation, of which twinning is quite commonly observed, as a mechanism that stores little energy of cold work while contributing significantly to the strain hardening (Bever et al., 1973; Padilla et al., 2007; Osovski et al., 2012). Additional phenomena may be induced by high rate straining of crystalline solid like dynamic recrystallization (Khan et al., 2007; Rittel et al., 2008; Osovski et al., 2012; Cerreta et al., 2012; Brown and Bammann, 2012). Also during phase transformations such as the conversion of austenite to martensite, well known to occur in a reversible way in pure iron (Rittel et al., 2006) or to develop in many ferrous alloys such as metastable austenitic steels of the 3XX series (Rodríguez-Martínez et al., 2011) or with high manganese content. In such cases, the measured temperature rise comprises the effects of exothermal phase transformations during which latent heat is released. When this is the case, a simple ratio of the thermal to mechanical power and work, into which this extraneous heat source is included, may yield effective values of $\beta_{\text {diff }}$ and $\beta_{\text {int }}$ which exceed 1 , as reported by Rittel et al. (2006) for pure iron, by Rusinek and Klepaczko (2009) for Transformation Induced Plasticity (TRIP) steels or by Jovic et al. (2006) for austenitic steels.

Considering specifically strain-induced phase transformations, the Strain Induced Martensitic Transformation (SIMT) is found e.g. in multiphase TRIP steels (Khan et al., 2012; Lim et al., 2012) and metastable austenitic grades (Lindgren et al., 2010; Kubler et al., 2011). These two alloys are frequently used by the industry for energy absorption in crash (Rodríguez-Martínez et al., 2010b; Andersson, 2005) or blast protection applications (Langdon and Schleyer, 2005a,b, 2006) due to their ductility and work hardening ability. This type of martensitic transformation occurs within a given range of temperatures $M_{s}^{\sigma}$ to $M_{d}$ covering the in-service conditions of TRIP and austenitic steels in many industrial applications. Above $M_{s}^{\sigma}$ the stress needed for martensite nucleation exceeds the flow stress of the austenitic phase, which should thus strain-harden to sustain martensite formation. As the temperature rises, austenite stability increases thereby limiting the transformation. Above $M_{d}$ martensite is not produced anymore (Lichtenfeld et al., 2006; Curtze et al., 2009).

Therefore a strong coupling is expected to exist between SIMT and heat generation in these alloys: SIMT contributes to heat through a latent heat term (exothermal transformation) and heat, in turn, hinders SIMT. Thus the latent heat released during martensitic transformation should modify the ratio of dissipated to plastic power. The weight of dislocation mediated (slip) plasticity in the inelastic deformation of the alloy should progressively decrease as austenite transforms into martensite, analogous to a twinned phase, thus leading to additional changes in the value of the stored energy of cold work. All these factors will most likely affect the value of the Taylor-Quinney coefficient upon deformation. However, this specific issue, barely reported in experimental work, has not been yet investigated and modeled systematically to the best of the authors' knowledge.

Therefore, we present a theoretical approach to evaluate the variability of the Taylor-Quinney coefficient in steels exhibiting SIMT. A constitutive model, previously proposed by Zaera et al. (2012) and now modified to account for the different heat rates, has been used. This model includes strain, strain rate and temperature effects in the phase transformation kinetics, and in the softening of each solid phase through the use of a homogenization technique. The model also allows considering the influence of stress state in the SIMT (Young, 1988). This work considers AISI 304 stainless steel, a reference metastable austenitic stainless steel for studying the SIMT process at high strain rates since it shows a large amount of transformed martensite even under adiabatic conditions (Rodríguez-Martínez et al., 2011). The new model sheds light on previous experimental results reporting unusual $(>1)$ values for the Taylor-Quinney coefficient (Rittel et al., 2006; Jovic et al., 2006; Rusinek and Klepaczko, 2009), apparently related to an exothermal phase transformation, through a differential treatment of the dissipative terms, namely latent heat and heat due to austenite and martensite plastic deformation. Likewise the model accounts for the strong coupling existing between martensitic transformation, strain, strain rate, stress state and heat release, thus allowing to perform a thorough analysis of their influence in the evolution of the ratio of dissipated to plastic power and work. The variability observed in $\beta_{\text {diff }}$ and $\beta_{\text {int }}$ shows the inherent limitations of assuming a constant value of the Taylor-Quinney coefficient when modeling high strain rate problems in alloys showing SIMT. On the contrary, taking into account the functional dependence of $\beta_{\text {diff }}$ and $\beta_{\text {int }}$ avoids considering an averaged value which may either under- or over-estimate the heat dissipated during the deformation process.

The paper is organized as follows. Section 2 shows the new thermodynamic approach proposed to calculate the variable Taylor-Quinney coefficient, highlighting the differences with the standard approach which considers a constant value. Section 3 provides a brief summary of the thermoviscoplastic constitutive equations used to model the SIMT. Section 4 describes the different finite element models developed to perform the study. In Section 5 the set of equations is integrated and the 
results are discussed revealing the key reasons for some experimental results. In addition, the influence of strain rate and stress state in the evolution of the Taylor-Quinney coefficient is presented. Next, a tensile and a compression dynamic test are simulated in Section 6. The results report valuable information about the validity of the experimental measurement of the Taylor-Quinney coefficient in dynamically phase transforming materials. The concluding section outlines the main outcomes of this study.

\section{Calculation of heat power}

In many thermo-mechanically coupled models the heat power is calculated by using a constant Taylor-Quinney coefficient. As said before this assumption is a rather crude one in general, as demonstrated by the experimental work, and different authors have derived models which consider its evolution (or that of its complementary part, the stored energy of cold work) with strain and/or strain-rate and/or temperature.

Some of these models were derived from a macroscopic point of view (Chaboche, 1993; Rosakis et al., 2000; Longère and Dragon, 2008b), while others start from microstructural considerations (Aravas et al., 1990; Zehnder, 1991; Mollica et al., 2001; Benzerga et al., 2005; Longère and Dragon, 2008a; Vivier et al., 2009). In some others (Yang et al., 2006; Stainier and Ortiz, 2010) a variational formulation of the coupled thermo-mechanical problem is proposed, which does not involve an a priori definition of a Taylor-Quinney coefficient; the intrinsic dissipation follows directly from the free energy potential and the dissipation potential, which suffices to define all aspects of the material behavior, the a posteriori value of the TaylorQuinney coefficient predicted by the theory resulting a function of both strain and strain-rate.

A testable difference between these previous models and the one presented herein is the consideration of a dynamically phase transforming material. The intrinsic dissipation in each of the constitutive phases is computed, as in the classical approach, as a constant fraction of the corresponding plastic work power - although more sophisticated approaches might be used. However, the variability of the Taylor-Quinney coefficient derives from the evolution of the phase fractions and from the latent heat released upon phase transformation, the last term being dependent on strain, strain rate, temperature and stress state through the constitutive equation used to account for phase transformation. The proposed model strives to provide complementary insight regarding heat generation in dynamically phase transforming alloys, in which the heat power might be greater than the intrinsic dissipation power.

Next, the classical model - constant Taylor-Quinney coefficient - and the proposed model will be described to emphasize the difference between both approaches. Finally, the adiabatic heat equation is stated to show the role of the Taylor-Quinney coefficient in the calculation of temperature increase. In the following equations, energies and powers are expressed in terms of unit volume.

\subsection{Constant Taylor-Quinney coefficient}

- Plastic power

$$
\dot{W}^{p}=\boldsymbol{\sigma}: \mathbf{d}^{p}
$$

where $\boldsymbol{\sigma}$ is the Cauchy stress and $\mathbf{d}^{p}$ the plastic rate of deformation tensor. In $J_{2}$ plasticity, the following expression in terms of the equivalent variables is also valid

$$
\dot{W}^{p}=\bar{\sigma} \dot{\bar{\varepsilon}}^{p}
$$

with $\bar{\sigma}=\sqrt{3 / 2 \mathbf{s}: \mathbf{s}}\left(\mathbf{s}\right.$ stress deviator tensor) and $\dot{\bar{\varepsilon}}^{p}=\sqrt{2 / 3 \mathbf{d}^{p}: \mathbf{d}^{p}}$.

- Heat power and work. Taylor-Quinney coefficients The heat power $\dot{Q}$ relates to the mechanical power through the differential Taylor-Quinney coefficient

$$
\beta_{\text {diff }}=\frac{\dot{Q}}{\dot{W}^{p}}
$$

If the relation is established between heat and plastic work we get the integral Taylor-Quinney coefficient

$$
\beta_{\text {int }}=\frac{\int \dot{Q} d t}{\int \dot{W}^{p} d t}
$$

$\beta_{\text {diff }}$ and $\beta_{\text {int }}$ may be experimentally determined by processing thermal measurements. In the classical approach a constant averaged value is commonly assumed for simulation tasks.

\subsection{New approach: variable Taylor-Quinney coefficient in dynamically phase transforming materials}

In the model presented herein, the Taylor-Quinney coefficient is considered to evolve upon the deformation process. We consider separately the plastic work in each phase and the latent heat. Powers per unit of corresponding phase volume have a tilde $\sim . \bar{\sigma}_{i}$ and $\overline{\bar{\varepsilon}}_{i}^{p}$ are the equivalent stress and the equivalent plastic strain rate for phase $i$, and homogenized values have 
the subscript ${ }_{\text {hom. }} f_{i}$ and $\beta_{i}$ are the volume fraction and the Taylor-Quinney coefficient for phase $i$. It should be noted that the scheme is set for a two phase structure austenite-martensite, however it could be easily extended for multiphase materials.

- Plastic power in the austenitic phase

$$
\dot{\tilde{W}}_{a}^{p}=\bar{\sigma}_{a} \dot{\bar{\epsilon}}_{a}^{p}
$$

- Plastic power in the martensitic phase

$$
\dot{\tilde{W}}_{m}^{p}=\bar{\sigma}_{m} \dot{\bar{\varepsilon}}_{m}^{p}
$$

- Plastic power

$$
\dot{W}^{p}=f_{a} \dot{\tilde{W}}_{a}^{p}+f_{m} \dot{\tilde{W}}_{m}^{p}
$$

or, in terms of homogenized stress and strain rate

$$
\dot{W}^{p}=\bar{\sigma}_{\text {hom }} \dot{\bar{\varepsilon}}_{\text {hom }}^{p}
$$

Using the homogenization model outlined in Section 3.3, Eqs. (7) and (8) provide the same values (Zaera et al., 2012).

- Heat power due to austenite plastic deformation

$$
\dot{\tilde{Q}}_{a}^{p}=\beta_{a} \dot{\tilde{W}}_{a}^{p}
$$

- Stored power in austenite

$$
\dot{\tilde{W}}_{a}^{s}=\left(1-\beta_{a}\right) \dot{\tilde{W}}_{a}^{p}
$$

- Heat power due to martensite plastic deformation

$$
\dot{\tilde{Q}}_{m}^{p}=\beta_{m} \dot{\tilde{W}}_{m}^{p}
$$

- Stored power in martensite

$$
\dot{\tilde{W}}_{m}^{s}=\left(1-\beta_{m}\right) \dot{\tilde{W}}_{m}^{p}
$$

- Latent heat power due to martensitic transformation

$$
\dot{Q}_{m}^{l}=L_{H} \dot{f}_{m}
$$

$L_{H}$ being the latent heat per unit volume of transformed austenite.

- Total heat power

$$
\dot{Q}=f_{a} \dot{\tilde{Q}}_{a}^{p}+f_{m} \dot{\tilde{Q}}_{m}^{p}+\dot{Q}_{m}^{l}
$$

\subsection{Temperature rate in adiabatic conditions}

The transient heat equation expresses the relationship between the spatial-temporal variation of the temperature $\theta$ and the dissipative and thermoelastic heat generation rates as follows

$$
k \nabla^{2} \theta-\rho c_{p} \dot{\theta}=-\beta_{\text {diff }} \dot{W}^{p}+\alpha_{\theta}(3 \lambda+2 \mu) \theta_{0} \mathbf{d}^{e}: \mathbf{1}
$$

where $k$ is the heat conductance, $\alpha_{\theta}$ the thermal expansion coefficient and $\theta_{0}$ the reference temperature. $\rho, c_{p}, \lambda$ and $\mu$ stand for the material's density, heat capacity and Lamé constants, all of them considered equal for austenite and martensite. $\mathbf{d}^{e}: \mathbf{1}$ is the trace of the elastic rate of deformation tensor. If adiabatic conditions prevail (no heat flux), as in the case of high-strain rate loading, and the thermo-elastic contribution is neglected, the heat equation takes the form

$$
\rho c_{p} \dot{\theta}=\beta_{\text {diff }} \dot{W}^{p}
$$

which permits to easily calculate the temperature rate once the plastic power is known. In the classical approach the TaylorQuinney coefficient takes a constant value whereas in the present approach a variable coefficient $\beta_{\text {diff }}$ is used. This allows to consider its functional dependence on strain, strain rate and stress state.

\section{A 3D constitutive model for metastable austenitic steels}

In the frame of the new approach, the previous equations rely on the value of following variables: martensite transformation rate $\dot{f}_{m}$, equivalent stress and equivalent plastic strain rate at each phase $i\left(\bar{\sigma}_{i}\right.$ and $\left.\dot{\bar{\varepsilon}}_{i}^{p}\right)$ and their corresponding homog- 
enized values ( $\bar{\sigma}_{\text {hom }}$ and $\dot{\bar{\varepsilon}}_{\text {hom }}^{p}$ ). These are determined using a constitutive model for analyzing martensite formation in austenitic steels deforming at high strain rates, that has been previously developed by Zaera et al. (2012). This model is based on the previous seminal works of Olson and Cohen (1975), Stringfellow et al. (1992) and Papatriantafillou et al. (2004, 2006) and includes modifications in the following items.

\subsection{Kinetics of SIMT}

Based on previous experimental works describing the sigmoidal shape of the transformation curves, and on the hypothesis of intersection of shear bands in austenite as the dominant mechanism of SIMT, Olson and Cohen (1975) proposed a 1-D physical model which can predict the strain-dependence of the kinetics of transformation.

$$
f_{m}=1-\exp \left[-\xi\left(1-\exp \left(-\alpha \bar{\varepsilon}_{a}^{p}\right)\right)^{n}\right]
$$

the volume fraction of martensite $f_{m}$ is thus defined by two physically-significant, temperature dependent parameters, $\alpha$ and $\xi$ and a fixed exponent $n$. The $\alpha$ parameter (which defines the course of shear band formation with strain) is temperature sensitive through its dependence on stacking fault energy. The $\xi$ parameter is proportional to the probability $P$ that an intersection will form an embryo, and this probability is temperature dependent through its relation to the chemical driving force.

The dependence of $\alpha$ with temperature has been defined through an exponential law which facilitates to capture the decrease of the transformation rate with increasing temperature within the temperature range in which the SIMT occurs

$$
\alpha(\Theta)=\alpha_{0}\left[1-\Theta \exp \left(\alpha_{1}\left(1-\Theta^{-1}\right)\right)\right]
$$

where $\alpha_{0}$ and $\alpha_{1}$ are constants. $\Theta$ is a normalized temperature related to the $\theta$ by the following expression

$$
\Theta=\frac{\theta-M_{s}^{\sigma}}{M_{d}-M_{s}^{\sigma}}
$$

Stringfellow et al. (1992) proposed a Gaussian cumulative distribution function to calculate the probability of martensitic nucleation

$$
P(g)=\frac{1}{\sqrt{2 \pi} s_{g}} \int_{-\infty}^{g} \exp \left[-\frac{1}{2}\left(\frac{\tilde{g}-\bar{g}}{s_{g}}\right)^{2}\right] d \tilde{g}
$$

$\bar{g}$ and $s_{g}$ being, respectively, the mean and standard deviation of the normal distribution function. $g$ is a normalized thermodynamic driving force for the martensitic transformation, dependent on temperature and triaxiality $\Sigma=(\boldsymbol{\sigma}: \mathbf{1}) /(3 \bar{\sigma})$. In this model the linearly temperature dependent formulation proposed by Stringfellow et al. (1992) for the thermodynamic driving force is replaced by an exponential equation

$$
g=g_{0} \exp \left(g_{1} \Theta\right)+g_{2} \Sigma
$$

where $g_{0}, g_{1}$ and $g_{2}$ are dimensionless constants. The new law provides greater temperature sensitivity of the rate of martensitic transformation. This becomes relevant at high strain rates where the temperature rise of the material results from the adiabatic character of the plastic deformation. According to the experimental results, reported by Rodríguez-Martínez et al. (2011) at high deformation rates - and therefore under significant temperature increase - small temperature variations lead to relevant differences on the volume fraction of martensite formed.

\subsection{Thermal strains}

The adiabatic increase in temperature during deformation at high strain rates may lead to non-negligible thermal strains. The rate of thermal deformation tensor is included in the generalized Hooke's law for hypoelastic-plastic materials

$$
\sigma^{\nabla}=\mathbf{C}: \mathbf{d}^{e}=\mathbf{C}:\left(\mathbf{d}-\mathbf{d}^{\theta}-\mathbf{d}^{p}\right)
$$

where $\boldsymbol{\sigma}^{\nabla}$ is an objective derivative of the Cauchy stress tensor, $\mathbf{d}, \mathbf{d}^{e}, \mathbf{d}^{\theta}$ and $\mathbf{d}^{p}$ are respectively the total, elastic, thermal and inelastic rate of deformation tensors, and $\mathbf{C}$ is the Hooke tensor for isotropic elasticity, defined by the elastic constants $\lambda$ and $\mu$. $\mathbf{d}^{\theta}$ is assumed to be isotropic

$$
\mathbf{d}^{\theta}=\alpha_{\theta} \dot{\theta} \mathbf{1}
$$

$\mathbf{d}^{p}$ is decomposed in the rate due to slip or twinning in the multiphase material $\mathbf{d}^{\text {slip }}$ and in the additional inelastic rate caused by the transformation process $\mathbf{d}^{\text {nucl }}$

$$
\mathbf{d}^{p}=\mathbf{d}^{s l i p}+\mathbf{d}^{\text {nucl }}
$$




\subsection{Yield stresses and plastic flow for austenite and martensite}

The thermal effects should be included in the model, regarding softening of each phase. Austenite and martensite are assumed to behave according to the following plastic potential including viscous and thermal effects

$$
\Psi_{i}=\frac{\sigma_{Y i}\left(\overline{\bar{\varepsilon}}_{i}^{p}\right) h\left(\theta_{i}\right) \dot{\bar{\varepsilon}}_{0 i}}{\frac{1}{m_{i}}+1}\left(\frac{\bar{\sigma}_{i}}{\sigma_{Y i}\left(\bar{\varepsilon}_{i}^{p}\right) h\left(\theta_{i}\right)}\right)^{\frac{1}{m_{i}}+1}
$$

Strain hardening is represented by a Ludwik law $\left(\sigma_{0 i}\right.$ reference yield stress, $H_{i}$ plastic modulus and $n_{i}$ strain hardening exponent)

$$
\sigma_{Y i}=\sigma_{0 i}+H_{i}\left(\bar{\varepsilon}_{i}^{p}\right)^{n_{i}}
$$

and a power law is chosen as the temperature-dependent function

$$
h\left(\theta_{i}\right)=\left(\frac{\theta_{i}}{\theta_{0 i}}\right)^{v_{i}}
$$

$v_{i}$ being the thermal sensitivity of phase $i$ and $\theta_{0 i}$ a reference temperature. Then the plastic potential leads to a power law for both viscous and thermal effects

$$
\bar{\sigma}_{i}=\left(\sigma_{0 i}+H_{i}\left(\overline{\bar{\varepsilon}}_{i}^{p}\right)^{n_{i}}\right)\left(\frac{\dot{\bar{\epsilon}}_{i}^{p}}{\dot{\bar{\varepsilon}}_{0 i}}\right)^{m_{i}}\left(\frac{\theta_{i}}{\theta_{0 i}}\right)^{v_{i}}
$$

This type of phenomenological formulation has been widely accepted in the literature to describe the thermo-viscoplastic behavior of metals and alloys subjected to dynamic loading. However, the authors are aware that a more sophisticated and physically-based description of the strain, strain rate and temperature sensitivities of both phases, austenite and martensite, would provide additional consistency to the model. For example, application of formulations based on thermal activation analysis and dislocation dynamics as those published elsewhere (Campbell and Harding, 1961; Kocks, 1975; Nemat-Nasser and Guo, 2003; Voyiadjis and Abed, 2005; Huang et al., 2009; Cai et al., 2010; Gao and Zhang, 2010) would certainly be considered an improvement with respect to the description provided by previous expression. Unfortunately, for calibration of most of such constitutive descriptions a large number of physical parameters has to be identified (e.g. initial density of dislocations, burgers vector, frequency factor, ...). To the best of the authors' knowledge, such parameters are not available in the open literature for the single phases which play a role in the behavior of the 304 steel.

The effective properties of viscoplastic heterogeneous material are calculated with the modified secant method proposed by Suquet (1995a,b, 1996)), and using the solving algorithm developed by Papatriantafillou et al. (2004).

A complete description of the model can be found in Zaera et al. (2012).

\section{Finite element models for the analysis of the evolution of the Taylor-Quinney coefficient}

In following sections we assess the validity of the proposed model through the analysis of the results of several initial boundary value problems (IBVP). The solution was obtained using the finite element code ABAQUS/Explicit (Simulia, 2010), well-suited to simulate high-speed, nonlinear, transient dynamic events. The code uses an explicit scheme, the central difference operator, which is only conditionally stable, i.e. the time step must be small enough to assure that the solution does not grow unbounded. The stability limit for the operator is inversely proportional to the highest natural frequency in the system. A global estimation algorithm, instead of an element by element estimate, is used to determine the maximum frequency of the entire model. This way, the effect of a contact condition - such as that in one of the IBVP proposed herein on the eigenvalue spectrum is taken into account. Additionally a small amount of damping is introduced by the code, reducing the stability limit to control high frequency oscillations. The time incrementation scheme is fully automatic and requires no user intervention.

In those models requiring more than one element to discretize the geometric domain, a mesh convergence study has been performed. The time evolution of different critical output variables, namely stress, strain and martensite volume fraction, were compared at specific locations against a measure of mesh density until the results converge satisfactorily.

For the integration of the above set of nonlinear rate constitutive equations in a finite deformation frame, incremental objectivity is achieved by rewriting them in a corotational configuration. Since the model was implemented in ABAQUS/Explicit (Simulia, 2010), the corotational coordinate system is defined by the polar rotation tensor and the material time derivative of the corotational stress tensor is given by the Green-Naghdi-McInnis stress rate. Taking advantage of the orthogonality of the rotation tensor, the symmetry of the Cauchy stress and rate of deformation tensors and the isotropy of the elastic tensor, the constitutive equations defined above, in which tensors are involved, are form-identical in the corotational configuration but with spatial variables now replaced by rotated variables. Moreover, all the constitutive equations of the model involving only scalars remain unchanged. An explicit scheme has been adopted to integrate the above equations. In a previous work (Zaera et al., 2012), the differential equations were discretized following a fully implicit algorithm. Nevertheless, due to the small time step characteristic of explicit codes, no difference was found in the results of the 
simulations using forward or backward integration. In addition, the explicit scheme used to integrate the constitutive model permitted a sharp decrease in the computational time.

The performance of the proposed approach was evaluated through two kinds of analysis. Firstly, different single-element models were considered. In absence of noticeable wave propagation effects, that has been confirmed a posteriori, the use of finite element models with a single element having one integration point permits to efficiently integrate the constitutive model under particular loading conditions. In these models the effect of a given specimen geometry is discarded and the results point out specifically the response of the constitutive model and of the thermodynamic approach. The study of the effect of strain, strain rate and stress state in the evolution of the Taylor-Quinney coefficient is performed in a neat manner. Secondly, the analysis is extended to two practical examples of dynamic tests, where the influence of the specimen geometry in the heat release is revealed.

The first study was performed using one $1 \times 1 \times 1 \mathrm{~mm}^{3}$ 8-node trilinear brick element with reduced integration, C3D8R in ABAQUS notation. Different equivalent plastic strain rates - from 1 to $10^{4} \mathrm{~s}^{-1}$ - and triaxialities - uniaxial tension, uniaxial compression and pure shear - were considered to analyze their influence on the evolution of both differential and integral Taylor-Quinney coefficients, since these parameters are know to modify the martensitic transformation process affecting heat generation. Fig. 1 shows the boundary conditions imposed to the element to define the different stress states.

In the second study two dynamic tests were simulated, one in tension and the other in compression. Dynamic tests are commonly used to determine the Taylor-Quinney coefficient because adiabatic conditions permits to neglect heat flux, thus simplifying the analysis of results. The geometry of the tensile specimen is taken from Rodríguez-Martínez et al. (2011). The mesh consists of 10,941 eight-node tri-linear brick elements with reduced integration. According to the considerations reported by Zukas and Scheffer (2000) the active part of the specimen has been meshed using elements whose aspect ratio was close to $1: 1: 1\left(\approx 1 / 3 \times 1 / 3 \times 1 / 3 \mathrm{~mm}^{3}\right)$. Fig. 2 shows the dimension of the tensile specimen and some features of the finite element model. The geometry of the compression specimen is taken from Jovic et al. (2006). The mesh consists of 5000 four-node axisymmetric bi-linear elements with reduced integration, CAX4R in ABAQUS notation. The specimen has been meshed using elements whose aspect ratio was $1: 1\left(=50 \times 50 \mu \mathrm{m}^{2}\right)$. The boundary conditions have been set using rigid surfaces which interact with the specimen through a penalty-type contact with a Coulomb friction coefficient $\mu_{f}=0.1$, a value commonly adopted for dynamic contact between steel-steel pairs (Hartley et al., 2007; Philippon et al., 2011). The viscous method available in ABAQUS/Explicit has been used in both tension and compression models to prevent hourglass deformation modes; the scale factor used for all hourglass stiffnesses was chosen equal to one. Fig. 3 shows the dimension of the compression specimen and some features of the finite element model.

The values of the model parameters for the AISI 304 grade are given in Zaera et al. (2012). In that work a constant TaylorQuinney coefficient was adopted; the contribution of latent heat due to phase transformation was taken into account through a value $\beta_{\text {diff }}=\beta_{i n t}=1$, greater than the commonly adopted for structural steels $(0.85-0.95)$. This permitted to consider both plastic work and martensitic transformation as heat sources in a simplified way. However, for the current approach a different value is taken for each phase. Plastic deformation in the austenite is governed by plastic slip, then $\beta_{a}=0.8$ was adopted to consider a significant value of cold work. Zehnder (1991) highlighted the increase of the TaylorQuinney coefficient with dislocation density. Nevertheless, aiming to focus exclusively on the effect of phase transformation in the variation of the Taylor-Quinney coefficient, $\beta_{a}$ was here considered constant upon deformation. Plastic deformation in the martensite is governed by twinning, a mechanism that stores little energy of cold work (Bever et al., 1973; Padilla et al., 2007; Osovski et al., 2012); then $\beta_{m}=1$ was adopted. According to Eqs. (9) and (11), $\beta_{a}$ and $\beta_{m}$ are differential coefficients, although they could be also interpreted as integral since they are constant. Regarding latent heat, the value proposed by Tomita and Iwamoto (1995) for austenite to martensite transformation was taken, $L_{H}=1.18 \cdot 10^{8} \mathrm{~J} / \mathrm{m}^{3}$. The stress-strain response derived from the former scheme (constant Taylor-Quinney coefficient) and the current scheme (variable TaylorQuinney coefficient) are compared with the experimental evidence reported by Rodríguez-Martínez et al. (2011) in Fig. 4. Both schemes provide analogous macroscopic material response for the loading conditions taken as a reference,
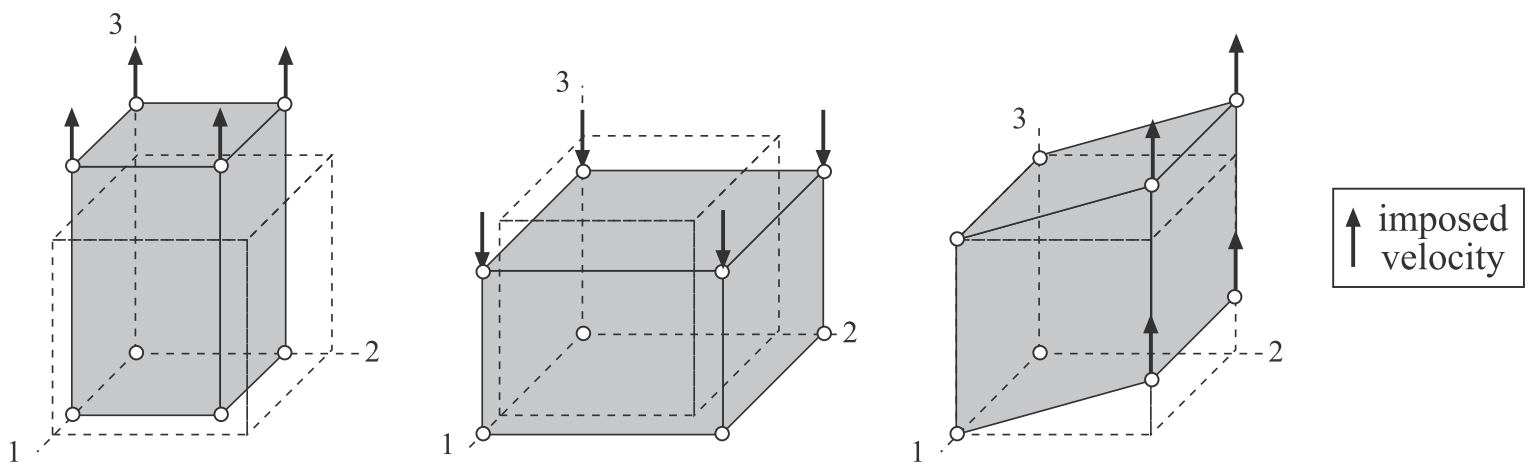

Fig. 1. Single element models and boundary conditions. Left: uniaxial tension $\Sigma=1 / 3$. Center: uniaxial compression $\Sigma=-1 / 3$. Right: pure shear $\Sigma=0$. 


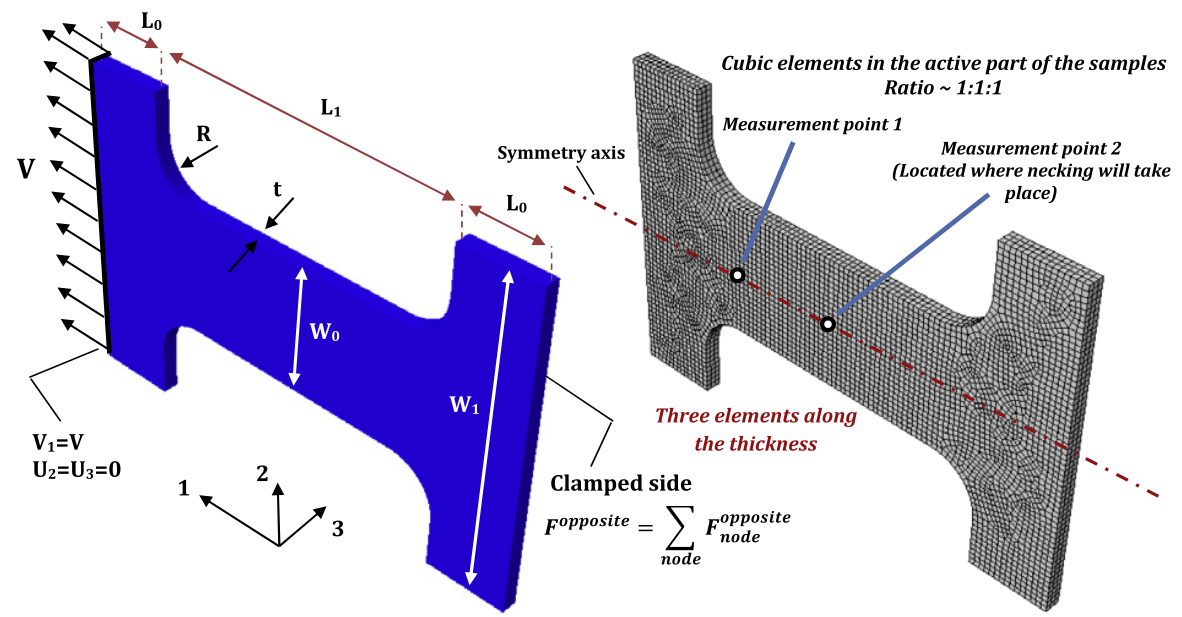

(a)

(b)

\begin{tabular}{cccccc}
\hline $\mathbf{L}_{\mathbf{0}}$ & $\mathbf{L}_{\mathbf{1}}$ & $\mathbf{W}_{\mathbf{0}}$ & $\mathbf{W}_{\mathbf{1}}$ & $\mathbf{R}$ & $\mathbf{t}$ \\
5 & 20 & 8 & 20 & 3 & 1 \\
\hline
\end{tabular}

Fig. 2. (a) Geometry and dimensions ( $\mathrm{mm}$ ) of the tensile specimen used in the numerical simulations. (b) Mesh configuration used in the numerical simulations.

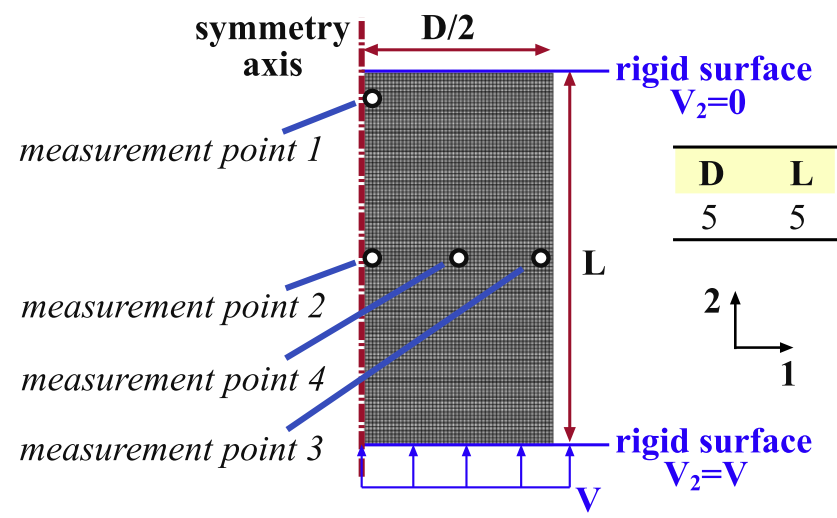

Fig. 3. Geometry and dimensions ( $\mathrm{mm}$ ) of the compression specimen used in the numerical simulations.

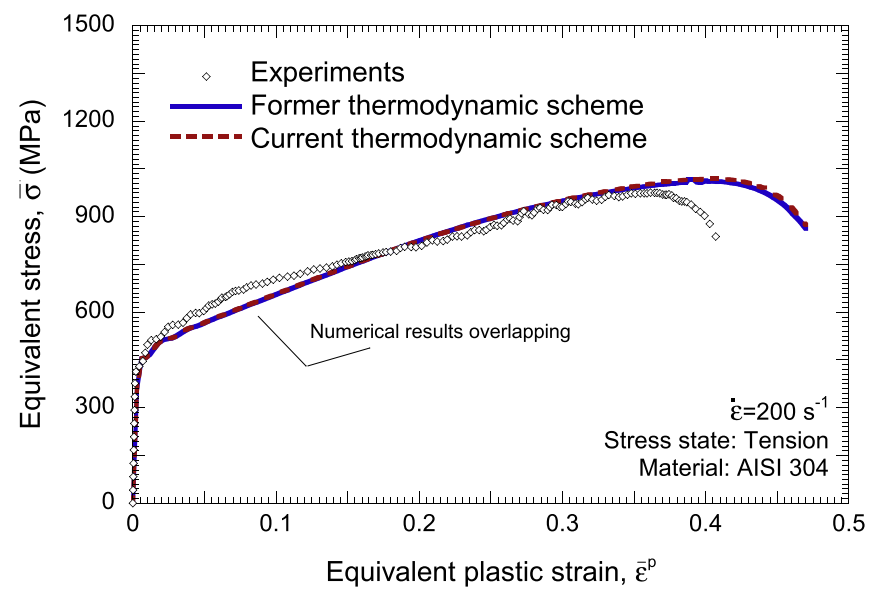

Fig. 4. Comparison between numerical predictions of the FE model and experiment performed at $\Sigma=1 / 3, \dot{\varepsilon}=200 \mathrm{~s}^{-1}$ (Rodríguez-Martínez et al., 2011). 
$\Sigma=1 / 3, \dot{\varepsilon}=200 \mathrm{~s}^{-1}$ and $\theta_{0}=293 \mathrm{~K}$. However only the new one permits to analyze the evolution of the ratio of dissipated to plastic power, and the influence of the loading conditions on it.

In the following sections, both differential and integral Taylor-Quinney coefficients will be analyzed. It is worth noting that their values are always calculated at integration points to emphasize the interest of studying the ratio of dissipated to plastic power - or work - as a local variable.

\section{The interplay between martensitic transformation and Taylor-Quinney coefficient in differential and integral forms}

In order to understand the variability of the Taylor-Quinney coefficient (either in differential or integral form) in steels exhibiting SIMT, the first step should aim to distinguish the heat sources involved in the thermomechanical framework and their relative contribution to the material temperature rise. Fig. 5 shows that the heat generated in the material during plastic deformation splits into that due to austenite straining, that due to martensite straining and the latent heat released due to the martensitic transformation. At the onset of loading, the temperature increase is tied to the austenite straining since the material in the undeformed configuration is fully austenitic. Then, martensitic transformation is triggered and the heat terms related to martensite deformation and transformation (the latter due to the latent heat release) come into play. The evolution of the latent heat upon deformation follows the same trend as the martensite transformation since the latent heat power was defined as a fraction of the martensitic transformation rate, Eq. (13). Once the phase transformation ends, the contribution of the latent heat to the overall temperature rise becomes constant. Interestingly, the contribution of the latent heat release is a non-negligible source of heat production which is comparable to the contribution of the heat generated due to martensite straining. One should note that the heat generation is a non-linear function of the material straining, which is identified as the source of a non-linear relation between the Taylor-Quinney coefficient (either in differential or integral form) and the plastic strain.

\subsection{Strain dependence of the Taylor-Quinney coefficient}

Next, Fig. 6 shows the martensite volume fraction together with the Taylor-Quinney coefficient in its differential $\beta_{\text {diff }}$ and integral $\beta_{\text {int }}$ forms upon plastic deformation at $\dot{\varepsilon}=200 \mathrm{~s}^{-1}$. Consider first the evolution of $\beta_{\text {diff }}$. The onset of loading defines $\beta_{\text {diff }}$ by the value assigned to the austenite, $\beta_{a}=0.8$. As deformation proceeds, the incipient martensitic transformation starts and $\beta_{\text {diff }}$ increases accordingly with plastic strain, reaching values in excess of 1 . The maximum rate of the martensite formation determines the maximum value of $\beta_{\text {diff }}$ as shown in Fig. 6. Beyond the maximum transformation rate $\beta_{\text {diff }}$ decreases with the decreasing transformation rate. At a certain level of material straining, the volume fraction of martensite reaches saturation and $\beta_{\text {diff }}$ becomes constant too. This stationary $\beta_{\text {diff }}$ does not coincides with the initial one due to the different values of the Taylor-Quinney coefficient assigned to martensite $\left(\beta_{m}=1.0\right)$ and austenite $\left(\beta_{a}=0.8\right)$. Yet, it will assume an intermediate value dictated by the volume fraction of each phase. The analysis can be further pursued considering the integral form of the Taylor-Quinney coefficient $\beta_{\text {int }}$, Fig. 6. Qualitatively $\beta_{\text {int }}$ evolves with plastic strain, as previously described for $\beta_{\text {diff }}$, while quantitatively a difference arises. The integral form of the Taylor-Quinney reaches values exceeding 1 due to the martensitic transformation, however the maximum value of $\beta_{\text {int }}$ does not coincide with the maximum value of the transformation rate. In addition, the end of the phase transformation (i. e. end of latent heat release) does not lead to constant $\beta_{\text {int }}$. Although the integral form of the Taylor-Quinney coefficient succeeds revealing the exothermal character of the martensitic

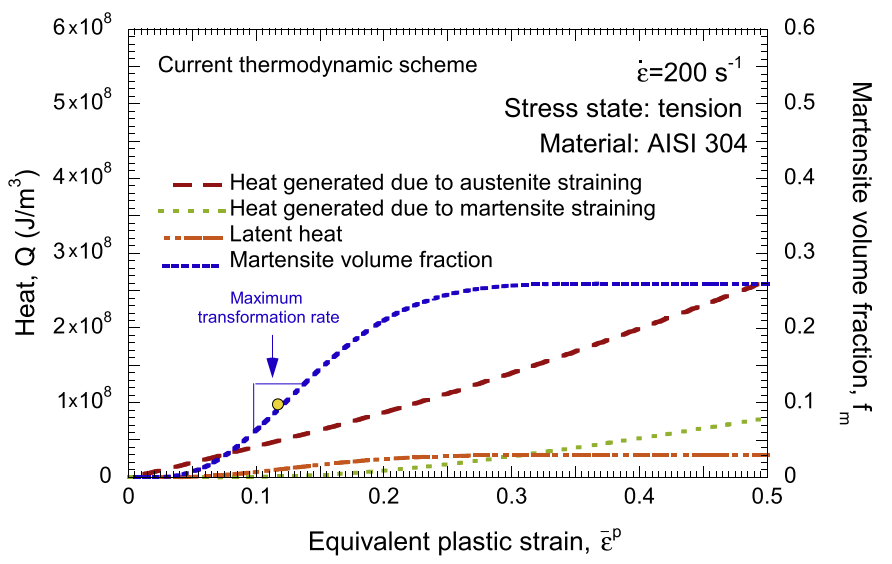

Fig. 5. Martensite volume fraction $f_{m}$ and heat generated due to austenite straining $\tilde{Q}_{a}^{p}$, due to martensite straining $\tilde{Q}_{m}^{p}$ and latent heat $Q_{m}^{l}$ as a function of the equivalent plastic strain $\bar{\varepsilon}^{p}$. 


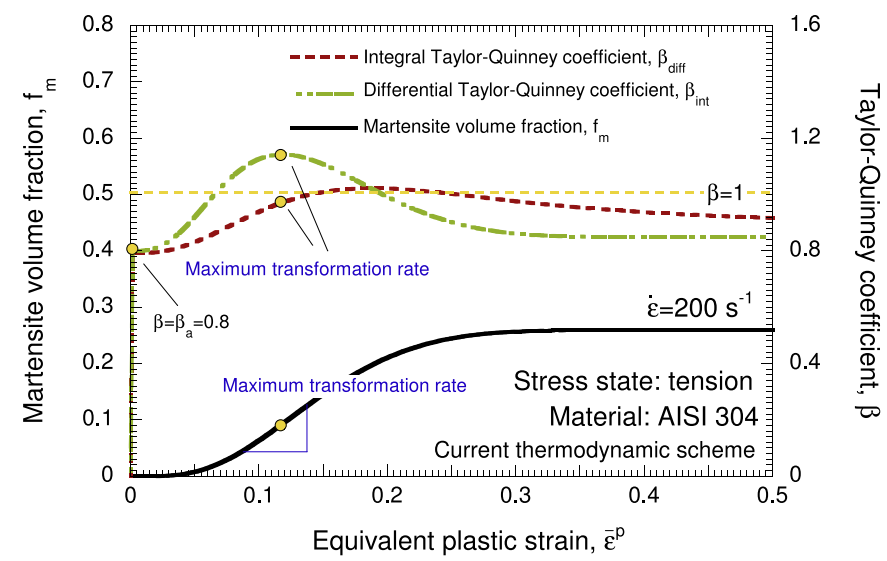

Fig. 6. Martensite volume fraction $f_{m}$ and Taylor-Quinney coefficient in differential $\beta_{\text {diff }}$ and integral $\beta_{\text {int }}$ forms as a function of the equivalent plastic strain $\bar{\varepsilon}^{p}$.

transformation (e.g. Rittel et al., 2006; Rusinek and Klepaczko, 2009) this factor cannot capture the interplay between phase transformation and heat release which has an inherent rate form.

The above analysis defines the differential Taylor-Quinney coefficient $\beta_{\text {diff }}$ as the main parameter for analysing the interplay between temperature rise and phase transformation. Thus, the next analysis is limited to the differential Taylor-Quinney coefficient. The impact on the variability of $\beta_{\text {diff }}$ of two key variables in the transformation kinetics such as strain rate and stress state is examined.

\subsection{Strain rate dependence of the Taylor-Quinney coefficient}

The influence of the strain rate on the model predictions was examined in tension within the range $10 \mathrm{~s}^{-1} \leqslant \dot{\varepsilon} \leqslant 10^{4} \mathrm{~s}^{-1}$. Fig. 7-a shows the evolution of the volume fraction of martensite as a function of both the strain and strain rate. One can note a decrease of the martensite volume fraction and the transformation rate with increasing loading rate. According to Rodríguez-Martínez et al. (2011) this is caused by the increasing temperature with loading rate due to the positive material strain rate sensitivity. Such a behavior determines the range of plastic strains for which the differential Taylor-Quinney coefficient exceeds 1 , Fig. $7 \mathrm{~b}$. Namely, the range of strains over which the condition $\beta_{\text {diff }}>1$ is fulfilled is reduced by increasing loading rates. Likewise, the maximum $\beta_{\text {diff }}$ experiences a continuous reduction with the strain rate. Interestingly, this rate dependence of the martensite volume fraction on strain rate leads to a systematic dependence of $\beta_{\text {diff }}$ on strain rate, in addition to the aforementioned dependence on plastic deformation.

\subsection{Stress triaxiality dependence of the Taylor-Quinney coefficient}

Three stress state conditions are considered: uniaxial tension $(\Sigma=1 / 3)$, uniaxial compression $(\Sigma=-1 / 3)$ and pure shear $(\Sigma=0)$. Fig. 8 shows the dependence of the martensite volume fraction $f_{m}$ and the differential Taylor-Quinney coefficient $\beta_{\text {diff }}$ on the plastic strain for the triaxiality values explored. The larger the stress triaxiality, the larger the transformation rate and the volume fraction of martensite formed during material straining (see Eq. 21), which is in agreement with the reported experimental evidence (Young, 1988; Lebedev and Kosarchuk, 2000; Turteltaub and Suiker, 2005). Then, due to the interplay between the transformation rate and $\beta_{\text {diff }}$, triaxiality appears to be a key factor which determines the evolution of $\beta_{\text {diff }}$ with plastic strain. By analogy with the strain rate dependence, it is found that the triaxiality controls the range of strains over which the condition $\beta_{\text {diff }}$ exceeds 1 , as well as its maximum value.

The single element analysis reveal that considering the exothermic character of the martensitic transformation leads to a functional dependence of the Taylor-Quinney coefficient (both differential and integral) on the plastic strain, strain rate and stress triaxiality.

Next, the model is applied to the simulation of dynamic tension and compression tests in full-size experimental specimens. The aim is to examine some problems associated with the determination of the Taylor-Quinney coefficient (either in differential or integral form) in regular samples commonly used in experimentation.

\section{Heat release in dynamic tests}

The dynamic tensile and compression tests, performed either with Split Hopkinson Bar or with high-speed servohydraulic machines, have been some of the techniques used to characterize the mechanical response of materials at high strain rates (Harding et al., 1960; Field et al., 2004; Rusinek et al., 2005). Force and displacement data permit to determine the work done 


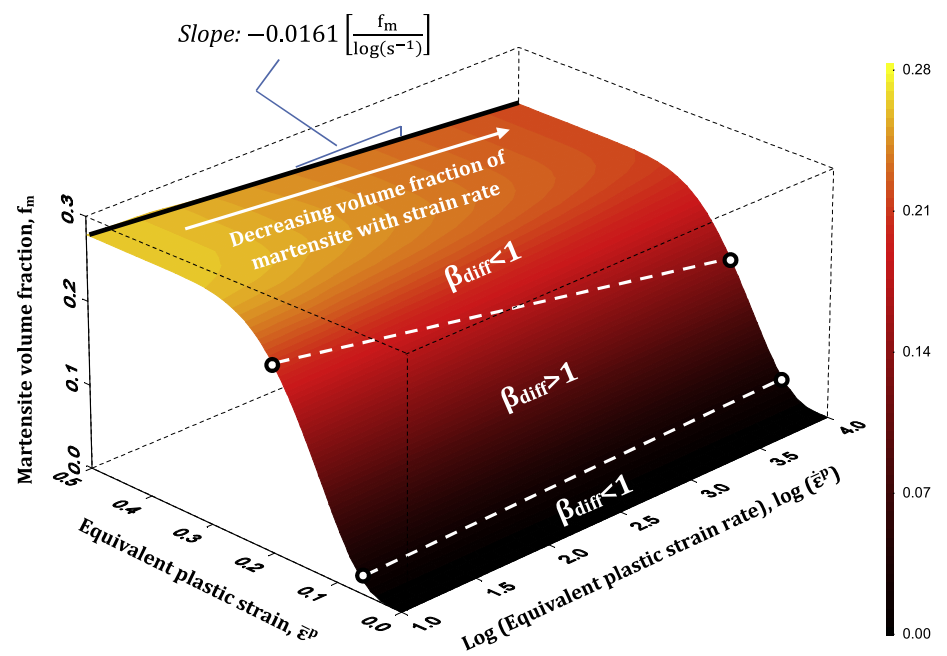

(a)

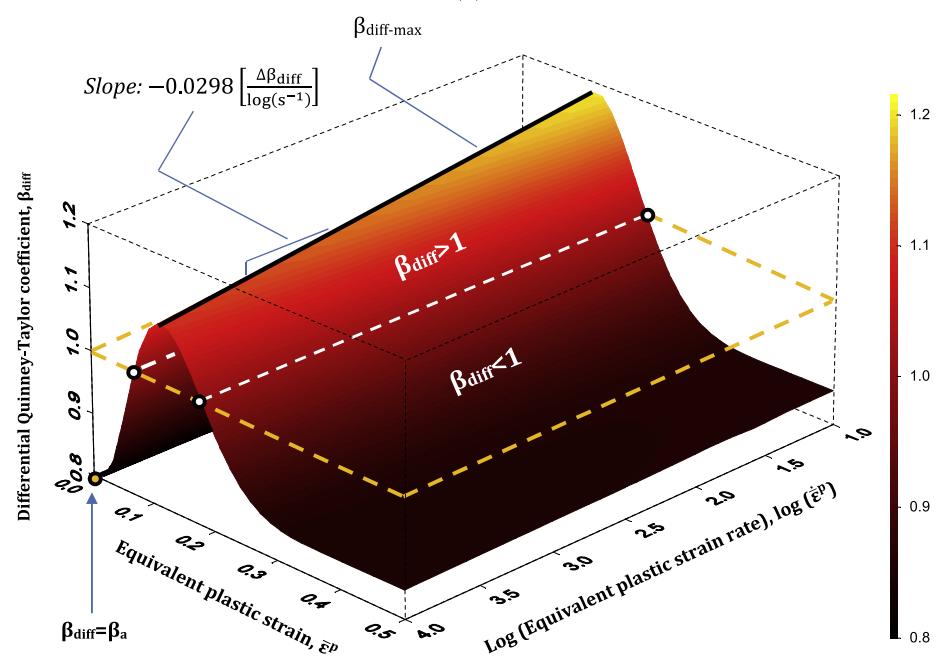

(b)

Fig. 7. (a) Martensite volume fraction $f_{m}$ and (b) differential Taylor-Quinney coefficient $\beta_{\text {diff }}$ upon equivalent plastic strain $\bar{\varepsilon}^{p}$ and strain rate $\overline{\bar{\varepsilon}}^{p}$ for $\Sigma=1 / 3$.

in plastic straining and temperature measurements permit to determine the heat dissipated upon deformation. Raw data are processed under the assumption of homogeneous fields along the specimen gauge. However, it is well known that stress and strain gradients arise in the tensile specimen, even before the onset of necking, and in the compression specimen due to barreling. Therefore the distribution of the local Taylor-Quinney coefficient is expected to be heterogeneous if a functional dependence is assumed. In the case of a steel exhibiting SIMT, the strong link between strain, strain rate, stress state and martensite nucleation will induce additional variability in the field of heat power to plastic power ratio. With the aim of analyzing these relations and the distribution of the Taylor-Quinney coefficient along the specimen, the results of the simulation of dynamic tests are presented next.

\subsection{Dynamic tensile test}

Fig. 9 shows the contours of martensite volume fraction rate and of differential Taylor-Quinney coefficient, obtained at two different instants of a dynamic tensile test performed at $500 \mathrm{~s}^{-1}$. The contours on the top (sample strain $\bar{\varepsilon}^{p}=0.10$ ) are representative of the initial stage in the process of martensitic transformation. Martensite is nucleating along the central part of the specimen and latent heat is contributing to increase $\beta_{\text {diff }}$ up to values close to 1.2. $\dot{f}_{m}$ is roughly homogeneous in the gauge, and so is the Taylor-Quinney coefficient. Homogeneity in this field ensures a proper calculation of $\beta_{\text {diff }}$ from the experimental measurements. However this is not true during the whole deformation process, even before the onset of necking. 


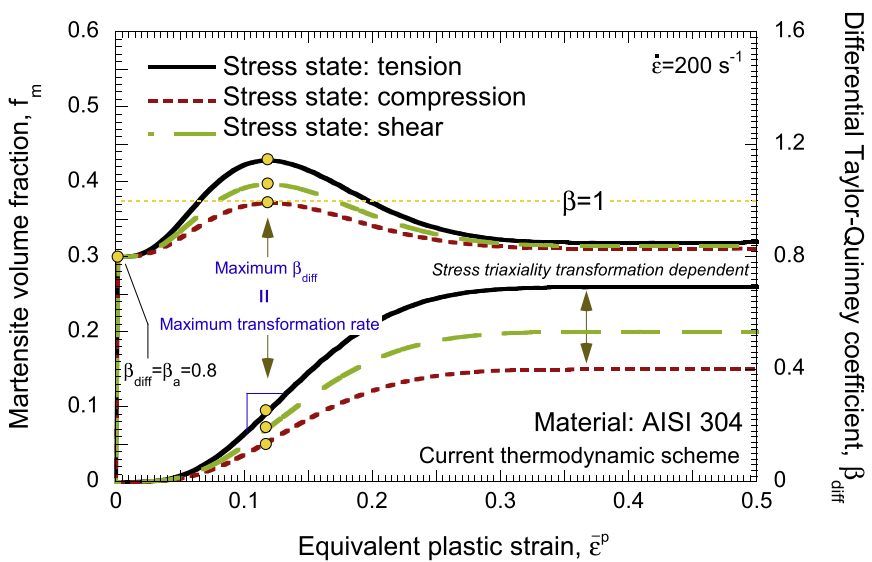

Fig. 8. Martensite volume fraction $f_{m}$ and differential Taylor-Quinney coefficient $\beta_{\text {diff }}$ as a function of the equivalent plastic strain $\bar{\varepsilon}^{p}$ for different stress triaxialities $\Sigma$.

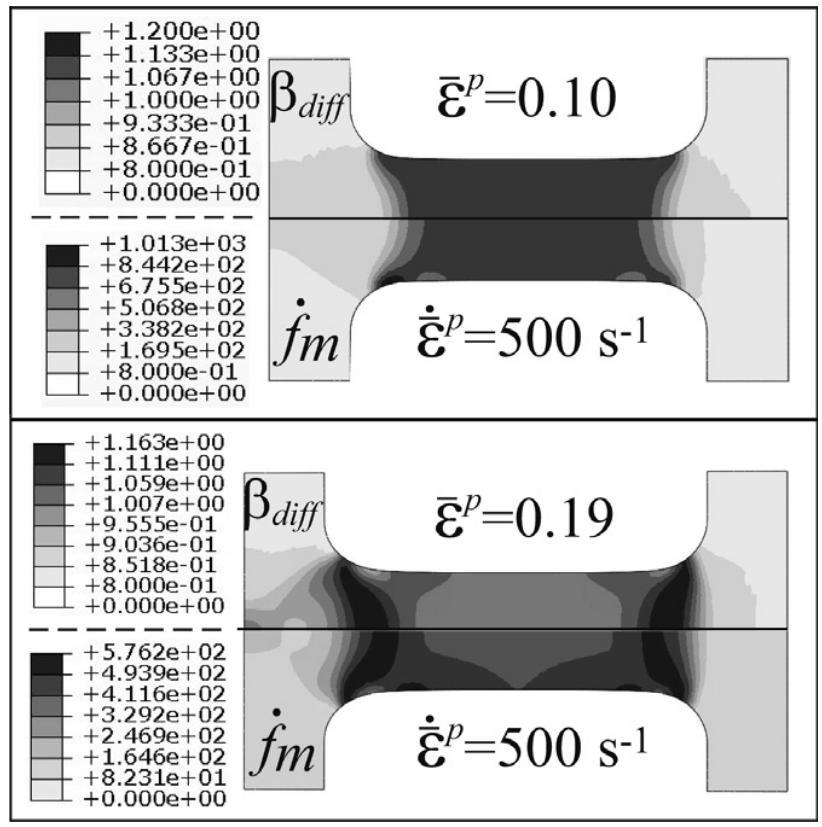

Fig. 9. Contours of martensite volume fraction rate $\dot{f}_{m}$ and of differential Taylor-Quinney coefficient $\beta_{\text {diff. }}$. Tensile test at $500 \mathrm{~s}^{-1}$.

The contours on the bottom (sample strain $\bar{\varepsilon}^{p}=0.19$ ) are representative of the next stage in the sample stretching, well prior to necking. Temperature at the specimen gauge has already exceeded $M_{d}$ and austenite is now stable in this region. At the same time martensite is forming on both sides of the gauge since the temperature in these regions is still below $M_{d}$. This heterogeneity in the transformation rate map causes strong differences in $\beta_{\text {diff }}$ along the specimen, with values close to 0.86 at the center (according to the final volume fraction of austenite and martensite) and close to 1.2 at both sides. Any attempt to calculate a value of the Taylor-Quinney coefficient from experimental measurements during this stage of the tensile test will not reflect the thermal heterogeneity. The differences in the evolution of both $\beta_{\text {diff }}$ and $\beta_{\text {int }}$ at the side or center of the gauge (points 1 and 2 in Fig. 2) are shown in Fig. 10. The transformation process is slower on the side and also ends later. Accordingly the Taylor-Quinney coefficients are delayed with respect to those corresponding to the center of the specimen.

\subsection{Dynamic compression test}

Similar results are also found in the dynamic compression tests. Fig. 11 shows the contours of Mises stress $\bar{\sigma}$, austenite strain rate $\dot{\bar{\varepsilon}}_{a}^{p}$, martensite transformation rate $\dot{f}_{m}$ and differential Taylor-Quinney coefficient $\beta_{\text {diff }}$ in the specimen deforming 

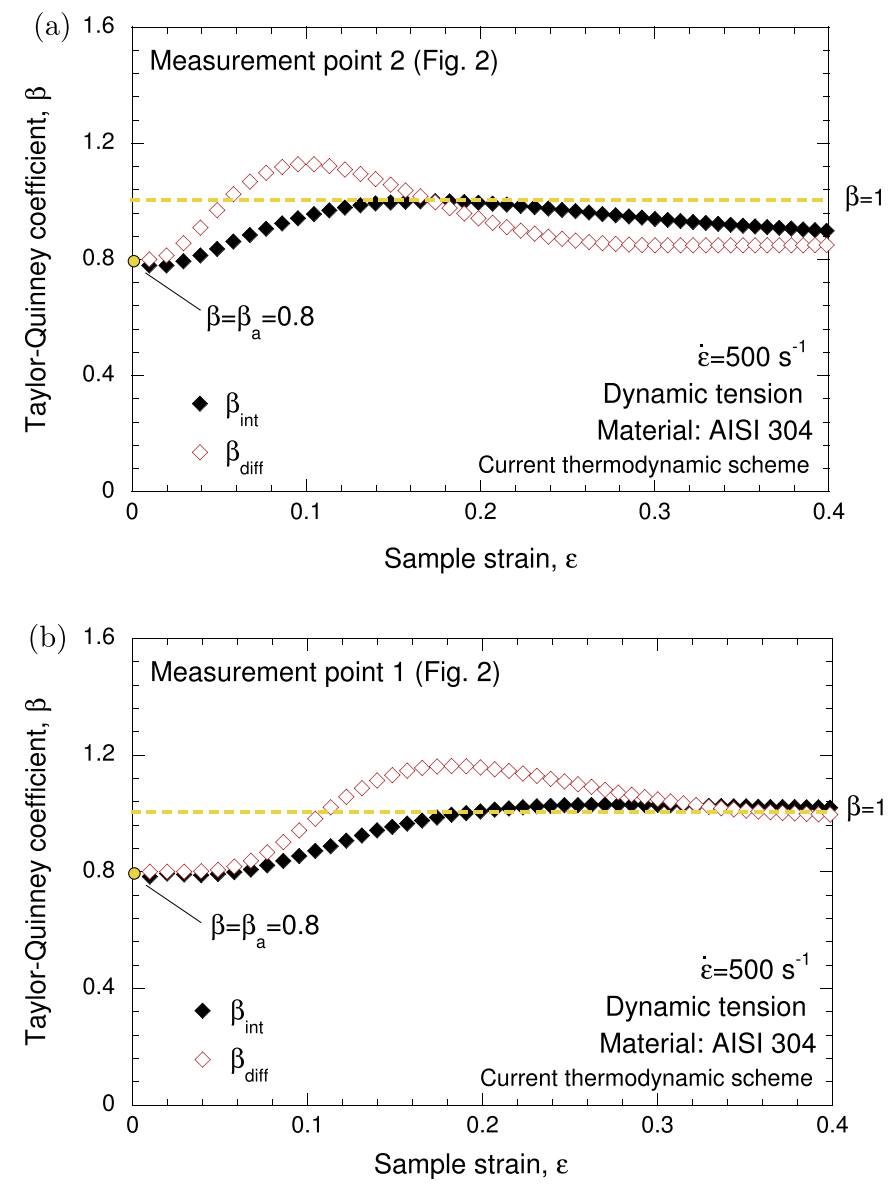

Fig. 10. Evolution of $\beta_{\text {diff }}$ and $\beta_{\text {int }}$ at two different points in the dynamic tensile test specimen: (a) center and (b) side.

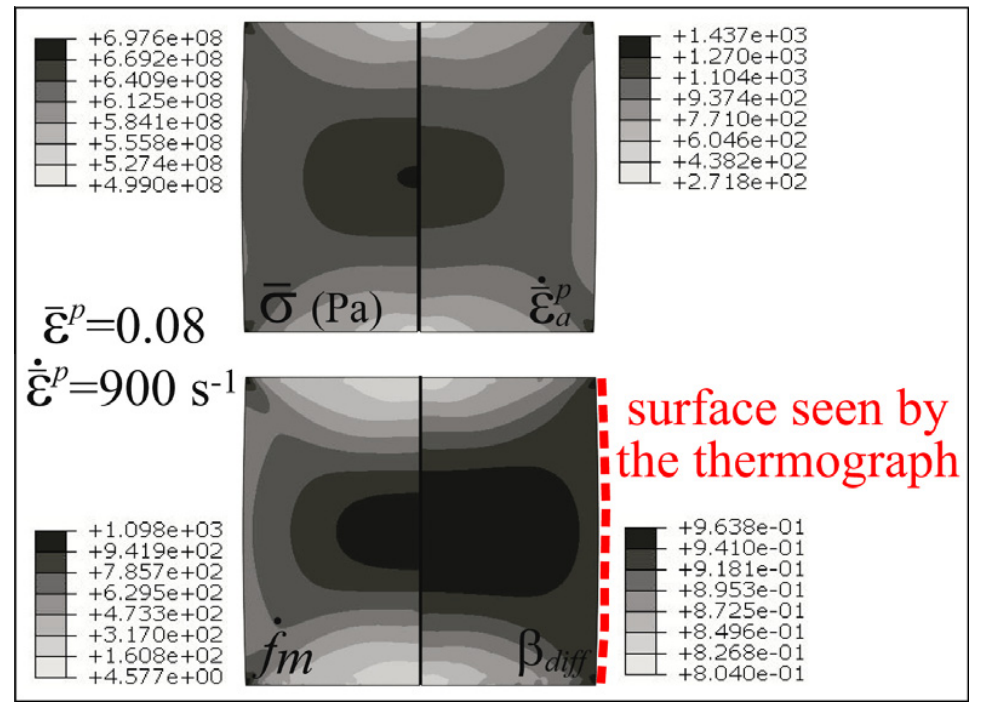

Fig. 11. Contours of martensite volume fraction rate $\dot{f}_{m}$ and of differential Taylor-Quinney coefficient $\beta_{\text {diff }}$. Compression test at $900 \mathrm{~s}^{-1}$. 
at $900 \mathrm{~s}^{-1}$. The shear stress induced, due to friction, at the contact surfaces leads to a heterogeneous stress field. Then austenite deforms at different rates causing a gradient in the transformation rate, since martensite nucleation is driven by deformation of the parent phase (Olson and Cohen, 1975; Stringfellow et al., 1992). The ratio of heat power to plastic power shows, therefore, a high variability along the specimen. The heterogeneous distribution of $\beta_{\text {diff }}$ may hinder its determination from experimental measurements. Although the surface of the specimen seen during the test presents a rather homogeneous value of the Taylor-Quinney coefficient, internally differences close to $20 \%$ may be present.

Just like in the case of the dynamic tensile test, the kinetics of martensite transformation vary along the compression specimen. The differences in the evolution of both $\beta_{\text {diff }}$ and $\beta_{\text {int }}$ at the side or center of the sample (points 1 and 2 in Fig. 3) are shown in Fig. 12. The transformation process goes slower at point 1 and also finishes later. Accordingly the Taylor-Quinney coefficients are delayed with respect to those corresponding to the center of the specimen.

Finally, we compare the trends shown by the model with the experimental results of Jovic et al. (2006) who performed dynamic compression tests on AISI 304L steel with a Split Hopkinson Pressure Bar. This steel also shows SIMT and presents slightly lower mechanical properties compared to 304. The temperature at the specimen surface was measured with an infrared detector allowing the determination of the differential Taylor-Quinney coefficient. Jovic et al. (2006) did not provide results for strains lower than $10 \%$ due to early lack of equilibrium of the specimen. Above this value, the experimental results showed a decrease of $\beta_{\text {diff }}$ with strain and a plateau at larger strains.

This trend is properly reproduced by the model as shown in Fig. 13, where the experimental results are compared with the numerical values taken at points 2, 3 and 4 of Fig. 3. According to the previous analysis, the decrease in the value of the Taylor-Quinney coefficient is due to the slowdown in the martensitic transformation and the plateau reveals the end of this process. It is worth noting the difference in the numerical predictions depending on the measurement point considered. As previously discussed, this is due to the heterogeneous strain field induced in the sample due to friction. The Taylor-Quinney coefficient measured in the free surface of the sample is delayed with respect to those corresponding to the center of the specimen.
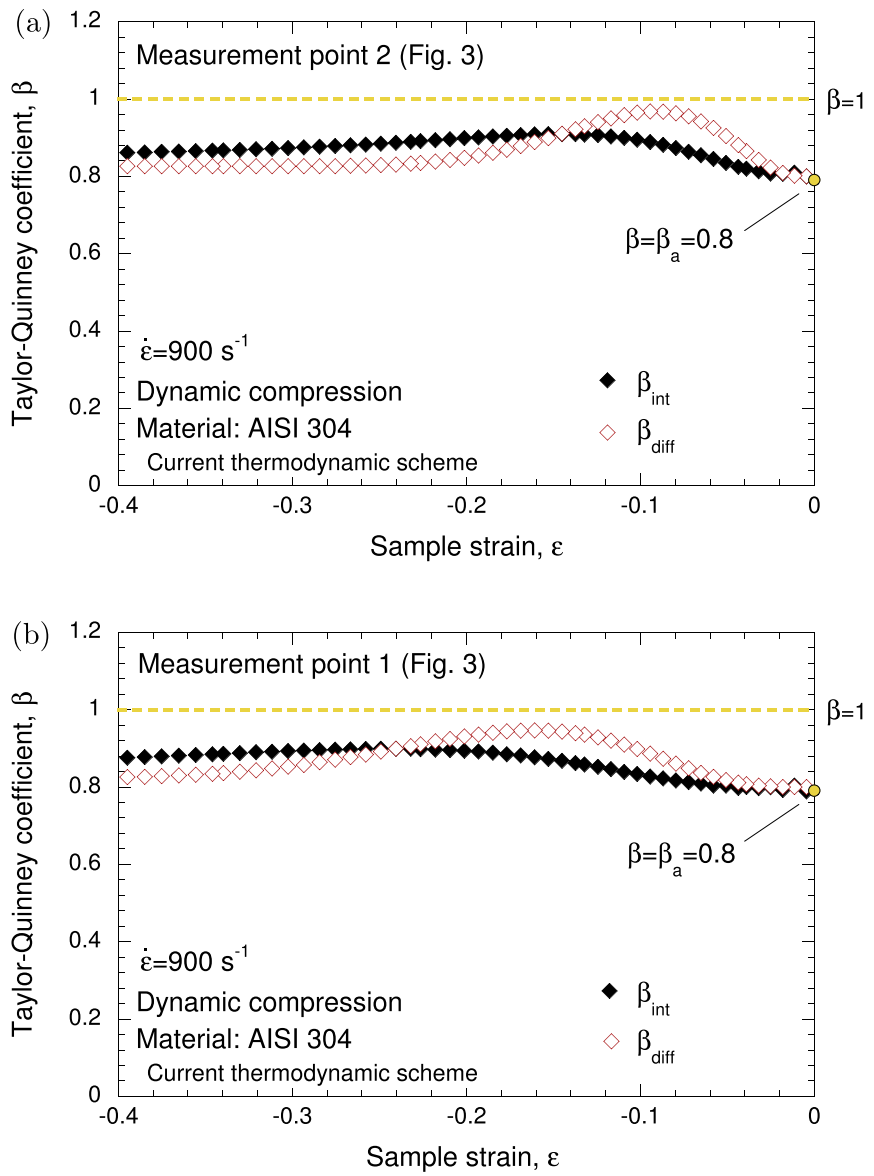

Fig. 12. Evolution of $\beta_{\text {diff }}$ and $\beta_{\text {int }}$ at two different points in the dynamic compression test specimen: (a) side Fig. 3 and (b) center Fig. 3. 


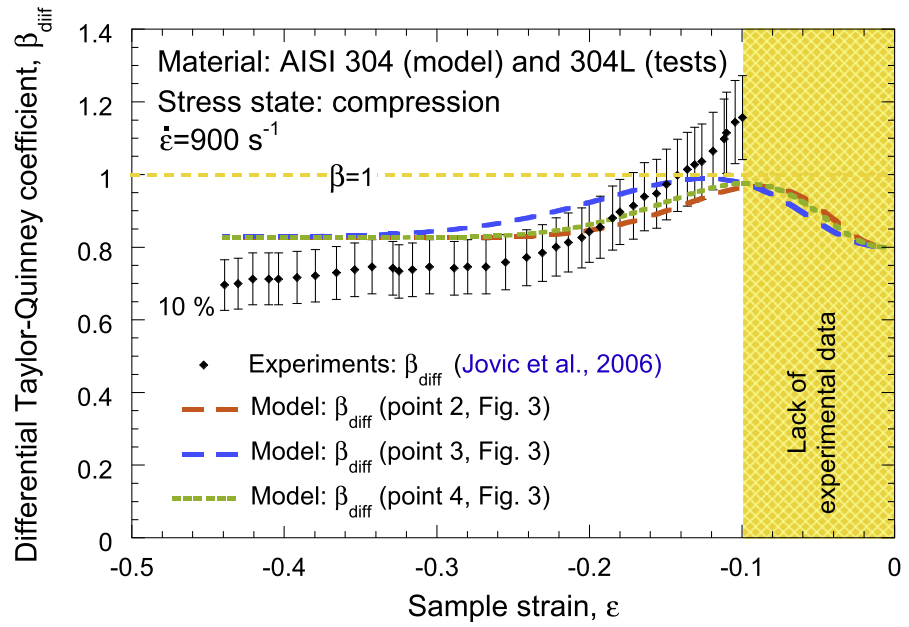

Fig. 13. Experimental (Jovic et al., 2006) and numerical (points 2, 3 and 4 in Fig. 3) values of the differential Taylor-Quinney coefficient $\beta_{\text {diff }}$. Compression test at $900 \mathrm{~s}^{-1}$.

\section{Conclusions and remarks}

The framework given herein presents a constitutive model developed for austenitic steels showing strain induced martensitic transformation. An original scheme is developed to calculate the heat power considering the heat dissipated separately in the deforming austenitic and martensitic phases and the heat released due to phase transformation. The model allows for a thorough analysis of the relations existing between stress state, strain rate, martensite transformation and heat upon straining. The first outcome of this framework is the possibility to theoretically predict the evolution of the heat to plastic power or work ratios upon straining. More specifically, this work addresses the Taylor-Quinney coefficient in its broadest sense, when extraneous heat sources other than those related to plastic work dissipation are active. As a result, some key experimental results on the variations of the Taylor-Quinney coefficient in phase transforming materials are rationalized. It is shown that the possibility of measuring values of $\beta_{\text {diff }}$ or $\beta_{\text {int }}$ greater than unity is related to the occurrence of a phase transformation through the release of latent heat, while the evolution of those factors (increase and subsequent decrease) follows the kinetics of the phase transformation.

One point hopefully clarified by the present study is that the Taylor-Quinney coefficient has to be considered as variable in phase transforming materials, depending on strain, strain rate and stress state. Thus a consistent thermo-viscoplastic constitutive model should account for these functional dependencies in order to get a reliable prediction of the temperature increase during the whole range of straining. In view of the large variation of $\beta_{\text {diff }}$ observed during a dynamic test, the use of a constant value, obtained experimentally by averaging the heat to plastic power ratio for a certain range of strain (and under certain strain rate and stress state conditions), may indeed lead to underestimation or overestimation of the temperature increase.

A central issue that has been overlooked in previous studies is the lack of homogeneity of the Taylor-Quinney coefficient along the specimen undergoing dynamic phase transitions, as confirmed in the present work. This unfortunately hinders precise and reliable determination of both $\beta_{\text {diff }}$ and $\beta_{\text {int }}$. The observed heterogeneity may affect or limit the accuracy of the global measurements based on spatially averaged stress and strain quantities.

The main conclusions that emerge from this work are as follows:

1. Phase transformation causes variability of the differential and integral Taylor-Quinney coefficients, due to the release of latent heat and to the change in the volume fractions of the crystalline structures.

2. Latent heat has to be considered as a relevant cause of temperature increase. By virtue of its contribution the heat-toplastic power and work ratios may exceed unity and, according to the model, the increase and subsequent decrease in its value is related do the transformation kinetics.

3. In steels exhibiting SIMT, strain, strain rate and triaxiality are identified as influential factors in the value of the TaylorQuinney coefficient.

4. The dependence of the Taylor-Quinney coefficient on state variables highlights the need to consider it as every other local variable. A solid exhibiting heterogeneous fields in the state variables, i.e. specimens used in dynamic testing, may also show spatial variability in the Taylor-Quinney coefficient. 


\section{Acknowledgements}

The researchers of the University Carlos III of Madrid are indebted to the Comunidad Autónoma de Madrid (Project CCG10-UC3M/DPI-5596)) and to the Ministerio de Ciencia e Innovación de España (Project DPI/2011-24068) for the financial support received which allowed conducting part of this work. D. Rittel acknowledges the support of Carlos III University with a Cátedra de Excelencia funded by Banco Santander during academic year 2011-2012.

\section{References}

Andersson, R., 2005. Deformation Characteristics of Stainless Steels. Ph.D. Thesis, Lulea University of Technology, Sweden.

Aravas, N., Kim, K., Leckie, F., 1990. On the calculations of the stored energy of cold work. Journal of Engineering Materials Technology 112, 465-470.

Baig, M., Khan, A., Choi, S., Jeong, A., 2012. Shear and multiaxial responses of oxygen free high conductivity (Ofhc) copper over wide range of strain-rates and temperatures and constitutive modeling. International Journal of Plasticity. http://dx.doi.org/10.1016/j.ijplas.2012.07.004.

Benzerga, A., Brechet, Y., Needleman, A., der Giessen, E.V., 2005. The stored energy of cold work: predictions from discrete dislocation plasticity. Acta Materialia 53, 4765-4779.

Bever, M., Holt, D., Titchener, A., 1973. The Stored Energy of Cold Work. Pergamon Press, London.

Bjerke, T., Li, Z., Lambros, J., 2002. Role of plasticity in heat generation during high rate deformation and fracture of polycarbonate. International Journal of Plasticity $18,549-567$.

Boley, B.A., Weiner, J.H., 1960. Theory of Thermal Stresses. J. Wiley and Sons, New York.

Bonnet-Lebouvier, A.S., Molinari, A., Lipinski, P., 2002. Analysis of the dynamic propagation of adiabatic shear bands. International Journal of Solids and Structures 39, 4249-4269.

Brown, A., Bammann, D., 2012. Validation of a model for static and dynamic recrystallization in metals. International Journal of Plasticity, 17-35.

Brünig, M., Driemeier, L., 2007. Numerical simulation of Taylor impact tests. International Journal of Plasticity 23, 1979-2003.

Cai, M.C., Niu, L.S., Ma, X.F., Shi, H.J., 2010. A constitutive description of the strain rate and temperature effects on the mechanical behavior of materials. Mechanics of Materials 42, 774-781.

Campbell, J.D., Harding, J., 1961. Response of Metals to High Velocity Deformation. Interscience, New York and London.

Cerreta, E., Bingert III, J., Gray, G., Trujillo, C., Lopez, M., Bronkhorst, C., Hansen, B., 2012. Microstructural examination of quasi-static and dynamic shear in high-purity iron. International Journal of Plasticity. http://dx.doi.org/10.1016/j.ijplas.2012.06.005.

Chaboche, J., 1993. Cyclic viscoplastic constitutive equations. Part ii: Stored energy-comparison between models and experiments. Journal of Applied Mechanics 60, 822-828.

Chrysochoos, A., Maisonneuve, O., Martin, G., Caumon, H., Chezeaux, J.C., 1989. Plastic and dissipated work and stored energy. Journal of Nuclear Engineering Design 114, 323-333.

Curtze, S., Kuokkala, V.T., Hokka, M., Peura, P., 2009. Deformation behavior of TRIP and DP steels in tension at different temperatures over a wide range of strain rates. Materials Science and Engineering A 507, 124-131.

Farren, W.S., Taylor, G.I., 1925. The heat developed during plastic extension of metals. Proceedings of the Royal Society of London A107, 422-451.

Field, J., Walley, S., Proud, W., Goldrein, H., Siviour, C., 2004. Review of experimental techniques for high rate deformation and shock studies. International Journal of Impact Engineering 30, 725-775.

Gao, C.Y., Zhang, L.C., 2010. A constitutive model for dynamic plasticity of FCC metals. Materials Science and Engineering A 527, 3138-3143.

Harding, J., Wood, E., Campbell, J., 1960. Tensile testing of materials at impact rates of strain. Journal of Mechanical Engineering Science 2, 88-96.

Hartley, R., Cloete, T., Nurick, G., 2007. An experimental assessment of friction effects in the split Hopkinson pressure bar using the ring compression test. International Journal of Impact Engineering 34, 1705-1728.

Hodowany, J., Ravichandran, G., Rosakis, A.J., Rosakis, P., 2000. Partition of plastic work into heat and stored energy in metals. Experimental Mechanics 40 , 113-123.

Huang, M., Rivera-Diaz-del-Castillo, P.E.J., Bouaziz, O., der Zwaag, S.V., 2009. A constitutive model for high-strain-rate deformation in fcc metals based on irreversible thermodynamics. Mechanics of Materials 41, 982-988.

Jovic, C., Wagner, D., Herve, P., Gary, G., Lazzarotto, L., 2006. Mechanical behaviour and temperature measurement during dynamic deformation on split Hopkinson bar of 304L stainless steel and 5754 aluminium alloy. Journal Physique IV 134, 1279-1285.

Kapoor, R., Nemat-Nasser, S., 1998. Determination of temperature rise during high strain rate deformation. Mechanics of Materials 27, 1-12.

Khan, A., Baig, M., Choi, S., Yang, H., Sun, X., 2012. Quasi-static and dynamic responses of advanced high strength steels: experiments and modeling. International Journal of Plasticity, 1-17.

Khan, A., Liu, H., 2012. Variable strain rate sensitivity in an aluminum alloy: response and constitutive modeling. International Journal of Plasticity 36, 1-14.

Khan, A.S., Kazmi, R., Farrokh, B., Zupan, M., 2007. Effect of oxygen content and microstructure on the thermo-mechanical response of three Ti-6Al-4V alloys: experiments and modeling over a wide range of strain-rates and temperatures. International Journal of Plasticity 23, 1105-1125.

Kocks, U.F., Argon, A.S., Ashby, M.F., 1975. In: Chalmers, B., Christian, J.W., Massalski, T.B. (Eds.), Thermodynamics and Kinetics of Slip, vol. 19. Pergamon Press, Oxford (Chapter Progress in Materials Science).

Kubler, R., Berveiller, M., Buessler, P., 2011. Semi phenomenological modelling of the behavior of trip steels. International Journal of Plasticity 27, 299-327.

Langdon, G.S., Schleyer, G.K., 2005a. Inelastic deformation and failure of profiled stainless steel blast wall panels. Part I: experimental investigations. International Journal of Impact Engineering 31, 341-369.

Langdon, G.S., Schleyer, G.K., 2005b. Inelastic deformation and failure of profiled stainless steel blast wall panels. Part II: Analytical modelling considerations. International Journal of Impact Engineering 31, 371-399.

Langdon, G.S., Schleyer, G.K., 2006. Deformation and failure of profiled stainless steel blast wall panels. Part III: Finite element simulations and overall summary. International Journal of Impact Engineering 32, 988-1012.

Lebedev, A.A., Kosarchuk, V.V., 2000. Influence of phase transformations on the mechanical properties of austenitic stainless steels. International Journal of Plasticity $16,749-767$.

Lichtenfeld, J.A., Mataya, M., Tyne, C.J.V., 2006. Effect of strain rate on stress-strain behavior of alloy 309 and 304L austenitic stainless steel. Metallurgical and Materials Transactions A 37A, 147-161.

Lim, H., Lee, M., Sung, J., Kim, J., Wagoner, R., 2012. Time-dependent springback of advanced high strength steels. International Journal of Plasticity 29, $42-59$.

Lindgren, L., Olsson, M., Carlsson, P., 2010. Simulation of hydroforming of steel tube made of metastable stainless steel. International Journal of Mechanical Sciences 26, 1576-1590.

Longère, P., Dragon, A., 2008a. Evaluation of the inelastic heat fraction in the context of microstructure-supported dynamic plasticity modelling. International Journal of Impact Engineering 35, 992-999.

Longère, P., Dragon, A., 2008b. Plastic work induced heating evaluation under dynamic conditions: critical assessment. Mechanics Research Communications 35, 135-141.

Ma, W., Li, X., Dai, L., Ling, Z., 2012. Instability criterion of materials in combined stress states and its application to orthogonal cutting process. International Journal of Plasticity, 18-40.

MacDougall, D., 2000. Determination of the plastic work converted to heat using radiometry. Experimental Mechanics 40, $298-306$. 
Mason, J.J., Rosakis, A.J., Ravichandran, G., 1994. On the strain and strain rate dependence of the fraction of plastic work converted into heat: an experimental study using high speed infrared detectors and the Kolsky bar. Mechanics of Materials 17, 135-145.

Miguélez, M.H., Zaera, R., Molinari, A., Cheriguene, R., Rusinek, A., 2009. Residual stresses in ortogonal cutting of metals: the effects of thermomechanical coupling parameters and of friction. Journal of Thermal Stresses 32, 269-289.

Molinari, A., 1997. Collective behavior and spacing of adiabatic shear bands. Journal of the Mechanics and Physics of Solids 45, 1551-1575.

Molinari, A., Cheriguene, R., Miguelez, H., 2010. Numerical and analytical modeling of orthogonal cutting: the link between local variables and global contact characteristics. International Journal of Mechanical Sciences 53, 183-206.

Mollica, F., Rajagopal, K., Srinivasa, A., 2001. The inelastic behavior of metals subject to loading reversal. International Journal of Plasticity $17,1119-1146$.

Nemat-Nasser, S., Guo, W.G., 2003. Thermomechanical response of DH-36 structural steel over a wide range of strain rates and temperatures. Mechanics of Materials 35, 1023-1047.

Oliferuk, W., Maj, M., Raniecki, B., 2004. Experimental analysis of energy storage rate components during tensile deformation of polycrystals. Materials Science and Engineering A 374, 77-81.

Olson, G.B., Cohen, M., 1975. Kinetics of strain-induced martensitic nucleation. Metallurgical Transactions A 6A, 791-795.

Osovski, S., Rittel, D., Landau, P., Venkert, A., 2012. Microstructural effects on adiabatic shear band formation. Scripta Materialia 66, 9-12.

Padilla, H.A., Smith, C.D., Lambros, J., Beaudoin, A.J., Robertson, I.M., 2007. Effects of deformation twinning on energy dissipation in high rate deformed zirconium. Metallurgical and Material Transactions A 38A, 2916-2927.

Papatriantafillou, I., Agoras, M., Aravas, N., Haidemenopoulos, G., 2006. Constitutive modeling and finite element methods for TRIP steels. Computer Methods in Applied Mechanics and Engineering 195, 5094-5114.

Papatriantafillou, I., Aravas, N., Haidemenopoulos, G., 2004. Finite element modelling of TRIP steels. Steel Research International 75, 732-738.

Philippon, S., Voyiadjis, G.Z., Faure, L., Lodygowski, A., Rusinek, A., Chevrier, P., Dossou, E., 2011. Device enhancement for the dry sliding friction coefficient measurement between steel 1080 and VascoMax with respect to surface roughness changes. Experimental Mechanics 51, 337-358.

Ravi-Chandar, K., 1995. On the failure mode transitions in polycarbonate under dynamic mixed mode loading. International Journal of Solids and Structures 32, 925-938.

Reyes, A., Langseth, M., Hopperstad, M., 2002. Crashworthiness of aluminum extrusions subjected to oblique loading: experiments and numerical analyses. International Journal of Mechanical Sciences 44, 1965-1984.

Rittel, D., 1998. Transient temperature measurement using embedded thermocouples. Experimental Mechanics 2, 73-79.

Rittel, D., 1999. The conversion of plastic work to heat during high strain rate deformation of glassy polymers. Mechanics of Materials 31, 131-139.

Rittel, D., Kidane, A.A., Alkhader, M., Venkert, A., Landau, P., Ravichandran, G., 2012. On the dynamically stored energy of cold work in pure single and polycrystalline copper. Acta Materialia 60, 3719-3728.

Rittel, D., Landau, P., Venkert, A., 2008. Dynamic recrystallization as a potential cause for adiabatic shear failure. Physical Review Letters $101,165501$.

Rittel, D., Ravichandran, G., Venkert, A., 2006. The mechanical response of pure iron at high strain rates under dominant shear. Materials Science and Engineering A 432, 191-201.

Rodríguez-Martínez, J.A., Pesci, R., Rusinek, A., Arias, A., Zaera, R., Pedroche, D., 2010a. Thermo-mechanical behaviour of TRIP 1000 steel sheets subjected to low velocity perforation by conical projectiles at different temperatures. International Journal of Solids and Structures 47, 1268-1284.

Rodríguez-Martínez, J.A., Rusinek, A., Pesci, R., 2010b. Experimental survey on the behaviour of AISI 304 steel sheets subjected to perforation. Thin-Walled Structures 48, 966-978.

Rodríguez-Martínez, J.A., Pesci, R., Rusinek, A., 2011. Experimental study on the martensitic transformation in AISI 304 steel sheets subjected to tension under wide ranges of strain rate at room temperature. Materials Science and Engineering: A 528, 5974-5982.

Rodríguez-Martínez, J.A., Rusinek, A., Chevier, P., Bernier, R., Arias, A., 2010c. Temperature measurements on ES steel sheets subjected to perforation by hemispherical projectiles. International Journal of Impact Engineering 37, 828-841.

Rojek, J., Zienkiewicz, O.C., Oñate, E., Posteka, E., 2001. Advances in FE explicit formulation for simulation of metalforming processes. Journal of Materials Processing Technology 119, 41-47.

Rosakis, P., Rosakis, A., Ravichandran, G., Hodowany, J., 2000. A thermodynamic internal variable model for the partition of plastic work into heat and stored energy in metals. Journal of the Mechanics and Physics of Solids 48, 581-607.

Rosenberg, Z., Dekel, E., 2004. On the role of material properties in the terminal ballistics of long rods. International Journal of Impact Engineering 30, 835851.

Rusinek, A., Klepaczko, J.R., 2009. Experiments on heat generated during plastic deformation and stored energy for TRIP steels. Materials and Design 30, $35-48$.

Rusinek, A., Zaera, R., Forquin, P., Klepaczko, J.R., 2008. Effect of plastic deformation and boundary conditions combined with elastic wave propagation on the collapse site of a crash box. Thin-Walled Structures 46, 1143-1163.

Rusinek, A., Zaera, R., Klepaczko, J.R., Cheriguene, R., 2005. Analysis of inertia and scale effects on dynamic neck formation during tension of sheet steel. Acta Materialia 53, 5387-5400.

Simulia, 2010. ABAQUS/Explicit User's Manual, version 6.10 Edition. Dassault Systèmes, Providence, USA.

Stainier, L., Ortiz, M., 2010. Study and validation of a variational theory of thermo-mechanical coupling in finite visco-plasticity. International Journal of Solids and Structures 47, 705-715.

Stringfellow, R.G., Parks, D.M., Olson, G.B., 1992. A constitutive model for transformation plasticity accompanying strain-induced martensitic transformations in metastable austenitic steels. Acta Metallurgica et Materialia 40, 1703-1716.

Suquet, P., 1995a. Overall properties of nonlinear composites: a modified secant moduli theory and its link to Ponte Castañeda's nonlinear variational procedure. Comptes Rendus de l'Acadèmie des Sciences. Sèrie IIb. Mècanique 320, 563-571.

Suquet, P., 1995b. Overall properties of nonlinear composites: secant moduli theories and variational bounds. In: Markov, K.Z. (Ed.), Continuum Models and Discrtete Systems. Proceedings of the 8th International Symposium. World Scientific Publishing Company, pp. 290-299.

Suquet, P., 1996. Overall properties of nonlinear composites: remarks on secant and incremental formulations. In: Pineau, A., Zaoui, A. (Eds.), Micromechanics of Plasticity and Damage of Multiphase Materials (IUTAM Symposium). Kluwer, pp. 149-156.

Taylor, G.I., Quinney, H., 1934. The latent energy remaining in a metal after cold working. Proceedings of the Royal Society of London 143, 307-326.

Tomita, Y., Iwamoto, T., 1995. Constitutive modelling of trip steel and its application to the improvement of mechanical properties. International Journal of Mechanical Sciences 37, 1295-1305.

Tresca, H., 1879. Sur la fluidité et l'écoulement des corps solides. Annales du Conservatoire des Arts et Métiers, 4.

Turteltaub, S., Suiker, A.S.J., 2005. Transformation-induced plasticity in ferrous alloys. Journal of the Mechanics and Physics of Solids 53, 1747-1788.

Vivier, G., Trumel, H., Hild, F., 2009. On the stored and dissipated energies in heterogeneous rate-independent systems: theory and simple examples. Continuum Mechanics and Thermodynamics 20, 411-427.

Voyiadjis, G.Z., Abed, F.H., 2005. Effect of dislocation density evolution on the thermomechanical response of metals with different crystal structures at low and high strain rates and temperatures. Archives of Mechanics 57, 299-343.

Yang, Q., Stainier, L., Ortiz, M., 2006. A variational formulation of the coupled thermo-mechanical boundary-value problem for general dissipative solids. Journal of the Mechanics and Physics of Solids 54, 401-424.

Young, C., 1988. Transformation Toughening in Phosphocarbide-Strengthened Austenitic Steels. Ph.D. Thesis, MIT, Cambridge, Massachusetts.

Zaera, R., Rodríguez-Martínez, J.A., Casado, A., Fernandez-Saez, J., Rusinek, A., Pesci, R., 2012. A constitutive model for analyzing martensite formation in austenitic steels deforming at high strain rates. International Journal of Plasticity 29, 77-101.

Zehnder, A.T., 1991. A model for the heating due to plastic work. Mechanics Research Communications 18, 23-28.

Zukas, J.A., Scheffer, D.R., 2000. Practical aspects of numerical simulations of dynamic events: effects of meshing. International Journal of Impact Engineering 24, 925-945. 